\title{
Quality of life in patients with systemic lupus erythematosus: the mediator role of psychological morbidity and disease activity
}

\section{Graça Pereira, Sílvia Duarte, Ana Ferraz, Martim Santos \& Liliana Fontes}

To cite this article: M. Graça Pereira, Sílvia Duarte, Ana Ferraz, Martim Santos \& Liliana Fontes (2020): Quality of life in patients with systemic lupus erythematosus: the mediator role of psychological morbidity and disease activity, Psychology, Health \& Medicine, DOI: 10.1080/13548506.2020.1728350

To link to this article: https://doi.org/10.1080/13548506.2020.1728350

曲 Published online: 24 Feb 2020.

Submit your article to this journal $\pi$

山 Article views: 19

Q View related articles ¿

View Crossmark data $ک$ 


\title{
Quality of life in patients with systemic lupus erythematosus: the mediator role of psychological morbidity and disease activity
}

\author{
M. Graça Pereira (iD) ${ }^{a}$, Sílvia Duarte ${ }^{b, c}$, Ana Ferraz ${ }^{d}$, Martim Santos ${ }^{d}$ and Liliana Fontes ${ }^{a}$
}

aSchool of Psychology, Research Center in Psychology (Cipsi), University of Minho, Braga, Portugal; bSchool of Psychology, University of Minho, Braga, Portugal; 'Psychiatry Department, Hospital De Braga, Braga, Portugal; 'School of Psychology, Research Group in Family Health \& Illness, University of Minho, Braga, Portugal

\begin{abstract}
Patients with systemic lupus erythematosus (SLE) experience chronic symptoms that negatively impact their quality of life (QoL). This study analyzed the variables that contributed to QoL in patients with SLE, including the mediating role of psychological morbidity and disease activity. This study used a transversal design and included 104 women with SLE. Participants answered several instruments assessing fatigue, psychological morbidity (depression and anxiety), body image, disease activity, and quality of life. The results showed that disease activity, fatigue severity, psychological morbidity and body image were associated with all domains of QoL. Additionally, psychological morbidity and disease activity mediated the relationship between body image and psychological morbidity. Also, disease activity mediated the relationship between body image and fatigue severity. According to the results, intervention in patients with SLE should focus on patients' psychological morbidity, particularly in the active phase of the disease. Body image, fatigue severity and psychological morbidity should be monitored in patients with SLE in order to promote QoL.
\end{abstract}

\section{ARTICLE HISTORY}

Received 30 July 2019

Accepted 29 January 2020

\section{KEYWORDS}

Systemic lupus

erythematosus; quality of

life; psychological morbidity

\section{Introduction}

Systemic Lupus Erythematosus (SLE) is a chronic, autoimmune, inflammatory, systemic, and non-contagious disease. Although its causes are not fully understood, genetic, endocrine, environmental, and immunological factors play a part in the onset and evolution of the disease (Kuo et al., 2015).

SLE may affect any race, age, and sex, but its family incidence can be 17 times higher than in the general population (Kuo et al., 2015). SLE predominantly affects females (90\%), especially Blacks and Asians, and its highest incidence is in women between 37-50 years old (Kuo et al., 2015). SLE manifestations vary widely, which often causes problems in differential diagnosis, especially when the first manifestations (inaugural episode) are neuropsychiatric (Govoni \& Bortoluzzi, 2017). Generally, the first sensations 
present as a generalized malaise: excessive fatigue, joint and muscular pains, headaches and fever (Rees et al., 2017).

SLE impacts quality of life (QoL) in its physical, psychological and social dimensions (Elera-Fitzcarrald et al., 2018). The major predictors of low QoL in SLE patients are socio-demographic factors such as older age, poverty and lower educational level (EleraFitzcarrald et al., 2018). Other important variables associated with QoL are SLE clinical manifestations, such as disease activity, organ damage, cutaneous, neuropsychiatric, renal and musculoskeletal manifestations, and prevalent comorbidities, like fibromyalgia and depression (Elera-Fitzcarrald et al., 2018). Santiago and Irún (2000) concluded that $53 \%$ of patients reported that their illness (and medication) greatly affected their daily lives, compromising fatigue, mood, physical appearance, marital relationships, sexual intercourse, ability to exercise, work outside the home, and perform household chores, among others. Regarding the impact of professional activity on QoL, employment status changes over the years. Santiago and Irùn (2000) found two years after diagnosis, that the proportion of employed patientshad decreased from $74 \%$ to $54 \%$ and over a two-year period, there was a $20 \%$ decrease of active SLE patients and working hours per week also decreased by $32.2 \%$.

Patients with SLE are at high risk for depression and anxiety (Zhang, Fu, Yin, Zhang, \& Shen, 2017), which are the most common psychological side effect in SLE (Palagini et al., 2013), especially in women (Macêdo, Appenzeller, \& Costallat, 2016), associated with disease activity. Minami et al. (2002) found significant correlations between disease activity and neurotic symptoms and concluded that psychological factors had an impact on the development of the disease and on patients' physical condition. Psychological morbidity has been associated with fatigue in patients with SLE. Donnelly et al. (2018) found a significant correlation between depression and fatigue.

Fatigue is one of the most common and disabling symptoms affecting more than $80 \%$ of patients with SLE (Palagini et al., 2013; Petri, Martin, Scheinberg, \& Furie, 2017) associated with a decreased functioning capacities and defined as a state of reduced ability to work after a period of mental or physical activity (Tench, McCurdie, White, \& D'Cruz, 2000). However, difficulties in measuring fatigue have prevented studies from fully understand its characteristics, mechanism, and therapeutics. Often, the cause of fatigue in SLE patients is unknown, although some factors are known to influence fatigue such as disease activity, mood disorders, inadequate sleeping patterns, weakened aerobic fitness, and the presence of fibromyalgia (Shaharir \& Gordon, 2016).

The relationship between fatigue and disease activity is controversial. Several researchers have argued that fatigued SLE patients show greater symptomatology compared with SLE patients without fatigue, and a significant correlation between fatigue and disease activity has been found (Zonana-Nacach et al., 2000). However, some studies showed no relationship. Tench et al. (2000) found that, in a sample of 120 women, $81 \%$ reported abnormal fatigue and $60 \%$ poor sleep quality, suggesting a relationship between fatigue, disease activity, sleep quality, anxiety, and depression. Jump et al. (2005) found that pain and depression were positive predictors of fatigue and Mcelhone, Abbott, and Teh (2006) suggested that fatigue was the best predictor of depression.

Changes in physical appearance or body image are associated with depression (Ji et al., 2012; Weinberg et al., 2018) and QoL (Weinberg et al., 2018) in patients with SLE. The 
effect of medication and treatments has been studied regarding their psychological impact. It has been suggested that corticoids have an impact on body image due to their side-effects, such as obesity, leading to emotional distress (Ji et al., 2012). Beckerman, Auerbach, and Blanco (2011) found that women with SLE presented a poor body image. Also, the development of depression and/or anxiety results in a decreased quality of life (Mok, Chan, \& Ho, 2016). Therefore, one may hypothesize that psychological morbidity may have a mediating role between body image and psychological QoL.

Body image is associated with QoL (Jolly et al., 2012) and disease activity influences QoL (Elera-Fitzcarrald et al., 2018; Etchegaray-Morales et al., 2017) and body image (Weinberg et al., 2018), thus disease activity may have a mediating role between body image and QoL. Since fatigue and disease activity are also related (Petri et al., 2017; Tench et al., 2000; Zonana-Nacach et al., 2000), disease activity may also have a mediating role between body image and fatigue that needs to be explored.

The present study was conceptually based on the Psychosocial Adaptation Model for Chronic Disease (Livneh, 2001). The model has as main outcome QoL and considers, in the process of illness adaptation, the influence of contextual variables, such as sociodemographic and clinical variables as well as the role of psychological variables that, in this case, were fatigue, body image, psychological morbidity, proposing mediation relationships among the variables. The aim of this study was to analyze: 1) the contribution of age, duration of the disease, disease activity, fatigue, body image, psychological morbidity regarding quality of life; 2) to analyze whether psychological morbidity mediated the relationship between body image/fatigue and QoL; and 3) whether disease activity mediated the relationship between body image/fatigue and Qol, in patients with SLE. We hypothesize that age, disease duration disease activity, psychological morbidity and body image will be related to all dimensions of QoL and that psychological morbidity and disease activity will mediate the relationship between body image/fatigue and QoL.

\section{Methods}

\section{Participants}

The sample included 104 women aged 25-63 (mean = 39; $S D=8.8$ ) with a partner. All patients were members of the 'Patients with Lupus Association' in the two major cities of Portugal and were invited by phone by one of the researchers to participate in the study if they met the inclusion criteria. The criteria for patient inclusion were: 1) diagnosis of SLE; 2) being female; 3) age between 20 and 65; 4) married or living with a partner. Participation was voluntary. The study used a transversal design.

\section{Instruments}

Sociodemographic and Clinical Questionnaire that evaluates SLE patients' demographic (age, schooling, occupation, and professional status), social, and clinical variables (time of SLE diagnosis, SLE symptoms, and number of hospitalizations).

Systemic Lupus Activity Questionnaire (SLAQ; Karlson et al., 2003; Research version of Pereira \& Duarte, 2006). This instrument consists of 26 items and evaluates the clinical status of SLE patients without using their clinical files. There are 24 items on disease 
activity evaluated on a Likert-type scale, a single Numerical Rating Scale (NRS) asking the patient to rate disease activity on a scale of $0-10$ over the past 3 months, and a Global Patient Assessment scale that includes a question about the presence and severity of SLE activity over the previous month. In this study, the global score was used, and the alpha was .85 .

Fatigue Severity Scale (FSS; Krupp, LaRocca, Muir-Nash, \& Steinberg, 1989; Portuguese version of Laranjeira, 2012). This self-report scale measures perception of fatigue in everyday situations (physical functioning, exercise, interference with work, family, or social life, among others) for different diseases. Participants answer several statements on how they felt during the previous week on a Likert-type scale ranging from 1 ('strongly disagree') to 7 ('strongly agree'). The Cronbach's alpha for the 9 items of the scale in the total sample was .88 and, in this study, .96.

Hospital Anxiety and Depression Scale (HADS; Zigmond \& Snaith, 1983; Portuguese version of Pais-Ribeiro et al., 2007). This instrument assesses anxiety and depression levels in non-psychiatric populations (Herrmann, 1997). It includes 14 items equally divided into two subscales: anxiety and depression. Anxiety items reflect a state of generalized anxiety, whereas depression items are more associated with an anecdotal state (Zigmond \& Snaith, 1983). Answers are given on a 4-point Likert-type scale ranging from 0 to 3 . High scores indicate high levels of anxiety and depression. In this study the alpha for the anxiety scale was .86 and for depression scale was .83 .

Body Image Scale (BIS; (Hopwood, Fletcher, Lee, \& Al Ghazal, 2001; Portuguese version of Cotrim \& Pereira, 2008). Composed of 10 items, this questionnaire includes affective (e.g., feeling self-conscious), behavioral (e.g., difficulty in looking at the naked body), and cognitive items (e.g., satisfaction with appearance). Answers range from 0 ('not at all') to 3 ('very much'), reflecting the severity of the impact the disease has on selfimage. The alpha in the present study was .95.

WHOQOL-BREF (Skevington, Lotfy, \& O'Connell, 2004; Portuguese version of VazSerra et al., 2006). This self-report scale assesses how people feel in relation to health and other life domains. It includes 26 items assessing four QoL domains: physical health, psychological, social relationships and environment. Items are scored on a 5-point Likert- type scale with highest scores indicating better QoL. In this study the alpha for the physical domain was $.87, .89$ for the psychological domain, .89 for social relations, and.84 for the environmental domain.

\section{Procedure}

This study followed all principles outlined in the Declaration of Helsinki and was approved by the Review Board of the Patients with Lupus Association (ADL), where data collection took place. The American Psychological Association and Institutional Review Board guidelines were followed in dealing with participants. Participants were informed about the objectives of the study and invited to participate if they met the inclusion criteria. Participation was voluntary and all patients signed an informed consent. 


\section{Data analysis}

To test the relationships between sociodemographic, clinical and psychological variables with QoL, the Pearson Correlation Coefficient was used since the variables presented a normal distribution. Data was analyzed using SPSS software (25 version). To test the variables that predicted QoL, a path analysis was performed. The initial model included the demographic and clinical variables (age, disease duration, and disease activity) as independent variables, the psychological variables (body image, psychological morbidity, fatigue) and QoL as a dependent variable. Modifications indexes were used to determine whether the model fit could be improved using the Chi-square, TLI, CFI, RMSEA indexes taking into consideration the appropriate reference values. The path analysis' models were done using the IBM statistics package SPSS AMOS (24 version).

\section{Results}

\section{Sample characteristics}

Of the total sample, $22.1 \%$ had four years of education, $24 \%$ nine years, $18.3 \%$ twelve years, and $26 \%$ had a college degree. Regarding professional status, the vast majority (74\%) was actively employed. The mean duration of SLE was 7 years. The main symptoms reported were joint pain $(80.1 \%)$, fatigue $(73.4 \%)$, and skin $(42.4 \%)$ and renal problems $(28.8 \%)$. Finally, $49 \%$ of patients had already been hospitalized due to SLE.

\section{Relationship between clinical, sociodemographic variables and QoL}

The results showed a negative correlation between disease activity, fatigue severity, body image, psychological morbidity with all domains of QoL. Therefore, more disease activity, fatigue, psychological morbidity and a poor body image were associated with lower QoL, in all domains. There were no associations between age, disease duration and the domains of QoL (Table 1).

\section{Path analysis model}

The results of the path analysis showed that the adjustment statistics for the initial model were $X^{2}=201.161(21)=9.722$, TLI $=.044$, CFI $=.554$ and RMSEA $=.291$ and in the adjusted final model indicated a good fit $\left(X^{2}=5.243(4)=1.311, \mathrm{TLI}=.978, \mathrm{CFI}=.991\right.$ and RMSEA = .055). The indirect effect of body image on psychological QoL was partially mediated by psychological morbidity (mediation effect $=-.128$; 95\% confidence

Table 1. Results of Pearson correlation between patients variables with domains of QoL.

\begin{tabular}{lcccccc}
\hline Variables & 1 & 2 & 3 & 4 & 5 & 6 \\
\hline 1. Physical QoL & -.100 & -.027 & $-.621^{* * *}$ & $-.466^{* * *}$ & $-.470^{* * *}$ & $-.459^{* * *}$ \\
2. Psychological QoL & -.043 & .005 & $-.633^{* * *}$ & $-.290^{* *}$ & $-.535^{* * *}$ & $-.546^{* * *}$ \\
3. Social Qol & -.183 & -.171 & $-.425^{* * *}$ & $-.287^{* *}$ & $-.527^{* * *}$ & $-.379^{* * *}$ \\
4. Environmental QoL & -.162 & -.079 & $-.501^{* * *}$ & $-.263^{* *}$ & $-.449^{* * *}$ & $-.380^{* * *}$ \\
\hline${ }^{*} p<.05 ;{ }^{* *} p<.01 ;{ }^{* * *} p<.001$ & & & & \\
1 - Age; 2 - Disease Duration; 3 - Disease Activity; 4 - Fatigue Severiy; 5 - Body Image; 6 - Psychological Morbidity
\end{tabular}


Table 2. Standardized indirect mediation effects.

\begin{tabular}{lllcccc}
\hline $\begin{array}{l}\text { Independent } \\
\text { Variables }\end{array}$ & $\begin{array}{c}\text { Mediator } \\
\text { Variable }\end{array}$ & $\begin{array}{c}\text { Dependent } \\
\text { Variable }\end{array}$ & $\begin{array}{c}\text { B mean indir- } \\
\text { ect effect }\end{array}$ & $\begin{array}{c}\text { SE of } \\
\text { mean }\end{array}$ & $\begin{array}{c}\text { 95\% Cl mean indirect effect } \\
\text { (low and upper) }\end{array}$ & $p$ value \\
\hline Body Image & Psychological & Psychological QoL & -.128 & .025 & $-.135 ;-.032$ & .001 \\
Morbidity & & & & & \\
Body Image & Disease Activity & Psychological QoL & -.223 & .032 & $-.195 ;-.068$ & .001 \\
Body Image & Disease Activity & Fatigue Severity & .147 & .094 & $.115 ; .487$ & .001 \\
\hline
\end{tabular}

\section{Initial Model}

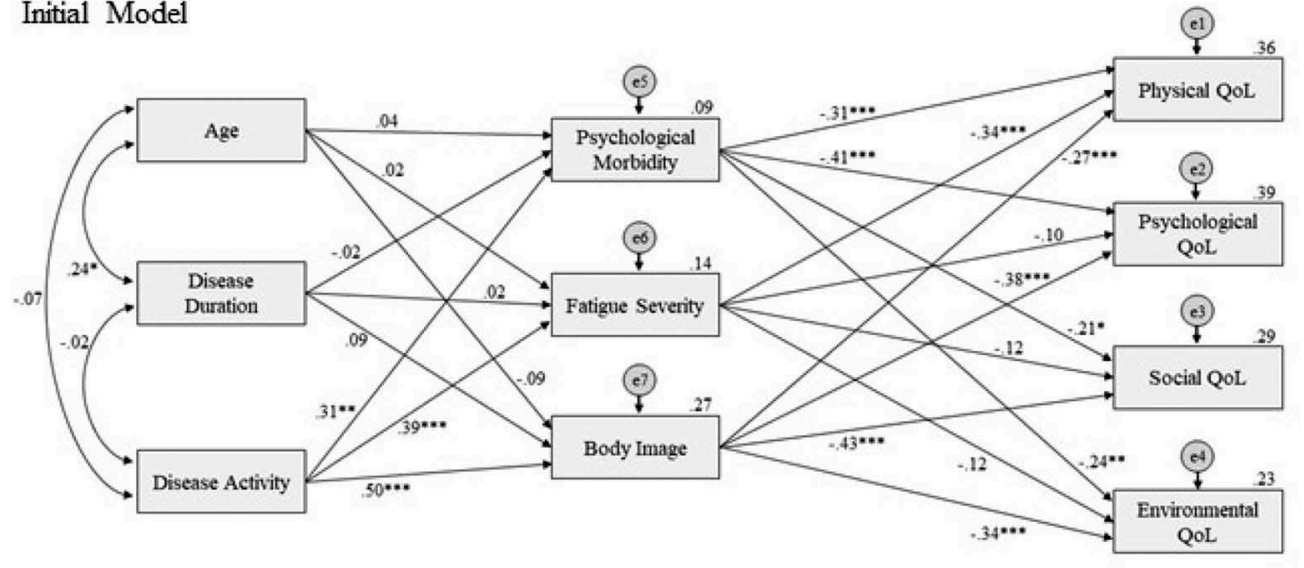

\section{Final Model}

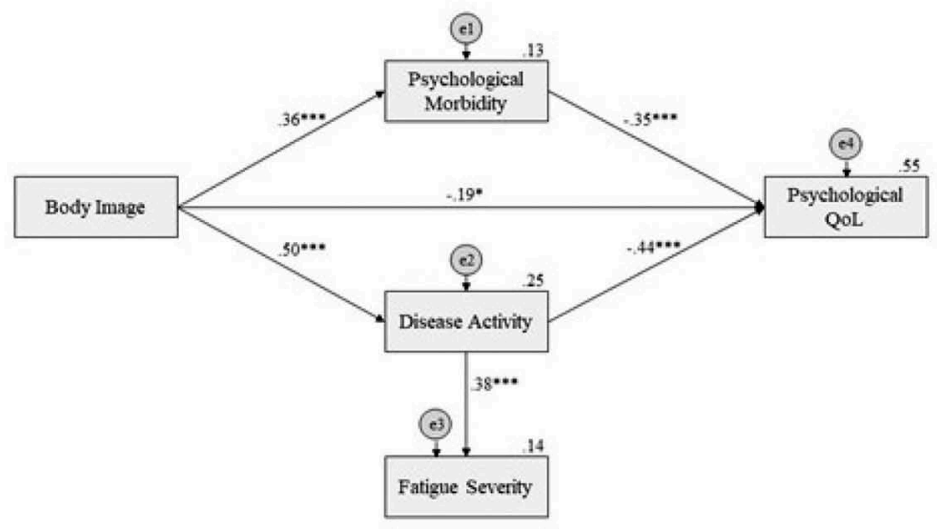

Figure 1. Path analysis model.

${ }^{*}<.05,{ }^{* *}<.01,{ }^{* * *}<.001$ Initial model adjustment: $X^{2}=201.161(21)=9.722, \mathrm{TLI}=.044, \mathrm{CFI}=.554$ and RMSEA $=.291$ Final model adjustment: $X^{2}=5.243(4)=1.311, \mathrm{TLI}=.978, \mathrm{CFI}=.991$ and RMSEA $=.055$

interval $=-.135$ to $-.032, \mathrm{p}<0.01$ ) and by disease activity (mediation effect $=-.223 ; 95 \%$ confidence interval $=-.195$ to $-.068, \mathrm{p}<.001$ ). In turn, the indirect effect of body image on fatigue severity was fully mediated by disease activity (mediation effect $=.190$; $95 \%$ confidence interval $=.115$ to $.487, \mathrm{p}<.001$, (Table 2 ). Figure 1 shows the initial and final model. 


\section{Discussion}

The results showed that higher disease activity, fatigue, psychological morbidity and body dissatisfaction were associated with worse QoL, in all domains. The literature has shown that disease activity is an important variable associated with poorer QoL (EleraFitzcarrald et al., 2018). Etchegaray-Morales et al. (2017) corroborated these results since QoL were directly associated with disease activity. In this study, high levels of disease activity were associated with low levels of QoL. In fact, patients reported that their illness greatly affected their daily lives (Santiago \& Irún, 2000). In turn, patients with fatigue severity have shown worse QoL. Tench et al. (2000) noted that fatigue was a significant predictor of QoL in patients with SLE, probably because was associated with lower fitness levels, reduced exercise capacity, reduced muscle strength, and greater disability (Tench et al., 2002), which negatively impacted QoL. Psychological morbidity was also related with QoL, with patients with depressive and anxious symptoms showing worse QoL. Kotsis et al. (2014) argued that psychological distress was also a predictor of QoL (Kotsis et al., 2014), probably because disease triggers the feeling of helplessness and exhaustion by everyday struggle (Olesińska \& Saletra, 2018). Internal fear, lack of comfort and security and the unpredictable course of the disease and prognosis are the biggest concerns (Olesińska \& Saletra, 2018). In this study, a greater body dissatisfaction was also associated with worse QoL, and the literature has shown that SLE patients presenting poorer body image and lower QoL than controls and those with cutaneous disease activity/damage and depression report poor QoL (Jolly et al., 2012). The effects of the disease on body image are often unsightly with implications on self-esteem and constrained feelings regarding appearance (Olesińska \& Saletra, 2018). However, further research is needed since body image literature in SLE is scarce and controversial (Jolly et al., 2012), being unclear its contribution to QoL.

Age and disease duration were not associated with QoL. These results are not in accordance with the literature showing older age (Elera-Fitzcarrald et al., 2018; Mcelhone et al., 2006; Plantinga, Lim, Bowling, \& Drenkard, 2016) and longer disease duration (Golder et al., 2017) to be associated with worse QoL (Elera-Fitzcarrald et al., 2018; Mcelhone et al., 2006; Plantinga et al., 2016). However, most studies show contradictory resultsregarding the influence of disease duration on QoL, emphasizing the importance of the effect of disease duration (Mcelhone et al., 2006). Additionally, age and QoL were not associated probably due to the younger age of this sample.

The results also showed that psychological morbidity partially mediated the relationship between body image and psychological QoL. Patients with poorer body image are more likely to present depressive and anxious symptomatology (Ji et al., 2012). The effects of SLE on QoL are comparable to other chronic diseases (Kiani \& Petri, 2010), thus in a study with a similar chronic illness (e.g. breast cancer) dissatisfaction with body image was associated with an increase in psychological morbidity (Przezdziecki et al., 2013). Psychological morbidity is a significant negative predictor of QoL (EleraFitzcarrald et al., 2018; Jolly et al., 2012; Mok et al., 2016). Likewise, in a study with chronically ill patients, psychological morbidity was negatively associated with psychological QoL (Santos, Sousa, Pereira, \& Pereira, 2019).

Disease activity also partially mediated the relationship between body image and psychological QoL. One may hypothesize that patients with body image dissatisfaction 
are more likely to perceive the presence and severity of SLE activity, which may result in a poorer psychological QoL (Elera-Fitzcarrald et al., 2018; Etchegaray-Morales et al., 2017). This result suggests that body image assumes a significant influence on disease activity, and alterations on physical appearance or body image, may increase patients' perceptions of SLE severity. Finally, disease activity fully mediated the relationship between body image and fatigue. As previously hypothesized, a poor body image may lead to a higher perception of disease activity, influencing patients' perceptions of fatigue severity. In accordance with the literature, fatigue appeared to be influenced by the presence of greater disease symptoms (Ahn \& Ramsey-Goldman, 2012; Zonana-Nacach et al., 2000).

Although causal inferences may not be derived in a transversal design, the fact that the model tested was theoretically driven, adds meaning to the interpretation of the results.

\section{Limitations}

This study has several limitations such as the sample size, the use of self-report measures, and its transversal design. Also, only the perception of patients was assessed. The present sample also included patients with a very low level of education and a longer disease duration.

\section{Conclusions}

Since psychological morbidity and disease activity were mediator variables, it is important in addition to controlling disease activity, that the intervention includes the identification of patients at risk of poor body image and psychology morbidity.

Body image and fatigue severity were also associated with all domains of Qol. As a result, it is important that intervention addresses body image and disease severity, particularly in patients with SLE, in the active phase, in order to promote QoL. In fact, a large body of evidence has shown that therapeutic interventions reduce psychological distress (Cooper et al., 2002) and improve perceived physical function (Greco, Rudy, \& Manzi, 2004), promoting QoL. For patients struggling with adaptation to SLE, cognitive behavioral stress management techniques should also be made available to adapt to an unpredictable disease such as SLE (Cooper et al., 2002).

This study should be replicated with patients with a higher level of education and more recently diagnosed. Future studies should also include patients with partners in order to access the role of family variables and also employ a longitudinal design to understand SLE impact over time.

\section{Disclosure statement}

No potential conflict of interest was reported by the authors.

\section{ORCID}

M. Graça Pereira (D) http://orcid.org/0000-0001-7987-2562 


\section{References}

Ahn, G. E., \& Ramsey-Goldman, R. (2012). Fatigue in systemic lupus erythematosus. International Journal of Clinical Rheumatology, 7(2), 217-227. doi:10.2217/ijr.12.4.

Beckerman, N., Auerbach, C., \& Blanco, I. (2011). Psychosocial dimensions of SLE: Implications for the health care team. Journal of Multidisciplinary Healthcare, 4, 63-72.

Cooper, G. S., Parks, C. G., Treadwell, E. L., St Clair, E. W., Gilkeson, G. S., Cohen, P. L., ... Dooley, M. A. (2002). Differences by race, sex and age in the clinical and immunologic features of recently diagnosed systemic lupus erythematosus patients in the southeastern United States. Lupus, 11(3), 161-167.

Cotrim, H., \& Pereira, M. G. (2008). Imagem corporal, morbilidade psicológica e qualidade de vida em doentes com cancro colorectal: Estudos das características psicométricas do Body Image Scale. In C. Machado, L. Almeida, M. Guisande, M. Gonçalves \& V. Ramalho (Eds.), Livro de Actas da XIII Conferência Internacional Avaliação Psicológica: Formas e Contextos (pp. A130). Braga: Universidade do Minho.

Donnelly, C., Cunningham, N., Jones, J. T., Ji, L., Brunner, H. I., \& Kashikar-Zuck, S. (2018). Fatigue and depression predict reduced health-related quality of life in childhood-onset lupus. Lupus, 27(1), 124-133.

Elera-Fitzcarrald, C., Fuentes, A., González, L. A., Burgos, P., Alarcón, G. S., \& Ugarte-Gil, M. (2018). Factors affecting quality of life in patients with systemic lupus erythematosus: Important considerations and potential interventions. Expert Review of Clinical Immunology, 1744666X.2018.1529566.

Etchegaray-Morales, I., Méndez-Martínez, S., Jiménez-Hernández, C., Mendoza-Pinto, C., Alonso-García, N., Montiel-Jarquín, A., ... García-Carrasco, M. (2017). Factors associated with health-related quality of life in Mexican lupus patients using the LupusQol. PloS One, 12 (1), e0170209.

Golder, V., Kandane-Rathnayake, R., Hoi, A., Huq, M., Louthrenoo, W., An, Y., ... Morand, E. (2017). Association of the lupus low disease activity state (LLDAS) with health-related quality of life in a multinational prospective study. Arthritis Research \& Therapy, 19(1). doi:10.1186/ s13075-017-1256-6

Govoni, M., \& Bortoluzzi, A. (2017). Lupus or not lupus? Neuropsychiatric symptom attribution in systemic lupus erythematosus. Rheumatology, 56(10), 1639-1640.

Greco, C. M., Rudy, T. E., \& Manzi, S. (2004). Effects of a stress reduction program on psychological function, pain, and physical function of systemic lupus erythematosus patients: A randomized controlled trial. Arthritis Care \& Research, 51(4), 625-626.

Herrmann, C. (1997). International experiences with the hospital anxiety and depression scale A review of validation data and clinical results. Journal of Psychosomatic Research, 42(1), 17-41.

Hopwood, P., Fletcher, I., Lee, A., \& Al Ghazal, S. (2001). A body image scale for use with cancer patients. European Journal of Cancer, 37(2), 189-197.

Ji, L., Lili, S., Jing, W., Yanyan, H., Min, W., Juan, X., \& Hongmei, S. (2012). Appearance concern and depression in adolescent girls with systemic lupus erythematous. Clinical Rheumatology, 31 (12), 1671-1675.

Jolly, M., Pickard, A., Mikolaitis, R., Cornejo, J., Sequeira, W., Cash, T., \& Block, J. (2012). Body image in patients with systemic lupus erythematosus. International Journal of Behavioral Medicine, 19(2), 157-164.

Jump, R., Robinson, M., Armstrong, A., Barnes, E., Kilbourn, K., \& Richards, H. (2005). Fatigue in systemic lupus erythematosus: Contributions of disease activity, pain, depression, and perceived social support. The Journal of Rheumatology, 32(9), 1699-1705.

Karlson, E., Daltroy, L., Rivest, C., Ramsey-Goldman, R., Wright, E., Partridge, A., ... Fortin, P. (2003). Validation of a systemic lupus activity questionnaire (SLAQ) for population studies. Lupus, 12(4), 280-286.

Kiani, A. N., \& Petri, M. (2010). Quality-of-life measurements versus disease activity in systemic lupus erythematosus. Current Rheumatology Reports, 12(4), 250-258. 
Kotsis, K., Voulgari, P., Tsifetaki, N., Drosos, A., Carvalho, A., \& Hyphantis, T. (2014). Illness perceptions and psychological distress associated with physical health-related quality of life in primary Sjögren's syndrome compared to systemic lupus erythematosus and rheumatoid arthritis. Rheumatology International, 34(12), 1671-1681.

Krupp, L., LaRocca, N., Muir-Nash, J., \& Steinberg, A. (1989). The fatigue severity scale. Archives of Neurology, 46(10), 1121.

Kuo, C., Grainge, M., Valdes, A., See, L., Luo, S., Yu, K., \& Doherty, M. (2015). Familial aggregation of systemic lupus erythematosus and coaggregation of autoimmune diseases in affected families. JAMA Internal Medicine, 175(9), 1518.

Laranjeira, C. A. (2012). Translation and adaptation of the fatigue severity scale for use in Portugal. Applied Nursing Research, 25(3), 212-217.

Livneh, H. (2001). Psychosocial adaptation to chronic illness and disability a conceptual framework. Rehabilitation Counseling Bulletin, 44(3), 151-160.

Macêdo, E., Appenzeller, S., \& Costallat, L. (2016). Gender differences in systemic lupus erythematosus concerning anxiety, depression and quality of life. Lupus, 25(12), 1315-1327.

Mcelhone, K., Abbott, J., \& Teh, L. S. (2006). A review of health related quality of life in systemic lupus erythematosus. Lupus, 15(10), 633-643.

Minami, Y., Sasaki, T., Arai, Y., Hosokawa, T., Hisamichi, S., \& Lupus, M. (2002). Psychological profiles and health status in Japanese female patients with systemic lupus erythematosus: The Miyagi lupus collaborative study. Journal of Epidemiology, 12(2), 55-63.

Mok, C. C., Chan, K. L., \& Ho, L. Y. (2016). Association of depressive/anxiety symptoms with quality of life and work ability in patients with systemic lupus erythematosus. Clinical and Experimental Rheumatology, 34(3), 389-395.

Olesińska, M., \& Saletra, A. (2018). Quality of life in systemic lupus erythematosus and its measurement. Reumatologia, 56(1), 45.

Pais-Ribeiro, J., Silva, I., Ferreira, T., Martins, A., Meneses, R., \& Baltar, M. (2007). Validation study of a Portuguese version of the hospital anxiety and depression scale. Psychology, Health \& Medicine, 12(2), 225-237.

Palagini, L., Mosca, M., Tani, C., Gemignani, A., Mauri, M., \& Bombardieri, S. (2013). Depression and systemic lupus erythematosus: A systematic review. Lupus, 22(5), 409-416.

Pereira, M. G., \& Duarte, S. (2006). Portuguese version of Systemic Lupus Activity Questionnaire. Unpublished manuscript, School of Psychology, University of Minho, Braga, Portugal.

Petri, M. A., Martin, R. S., Scheinberg, M. A., \& Furie, R. A. (2017). Assessments of fatigue and disease activity in patients with systemic lupus erythematosus enrolled in the Phase 2 clinical trial with blisibimod. Lupus, 26(1), 27-37.

Plantinga, L., Lim, S. S., Bowling, C. B., \& Drenkard, C. (2016). Association of age with health-related quality of life in a cohort of patients with systemic lupus erythematosus: The Georgians organized against lupus study. Lupus Science \& Medicine, 3(1), e000161.

Przezdziecki, A., Sherman, K. A., Baillie, A., Taylor, A., Foley, E., \& Stalgis-Bilinski, K. (2013). My changed body: Breast cancer, body image, distress and self-compassion. Psycho-oncology, 22(8), 1872-1879.

Rees, F., Doherty, M., Lanyon, P., Davenport, G., Riley, R., Zhang, W., \& Grainge, M. (2017). Early clinical features in systemic lupus erythematosus: Can they be used to achieve earlier diagnosis? A risk prediction model. Arthritis Care \& Research, 69(6), 833-841.

Santiago, A., \& Irún, J. (2000). La calidad de vida de los enfermos de lupus sistémico de Cantabria [Quality of life of patients with systemic lupus of Cantabria]. Cantabria: T.G.D. Santander.

Santos, M., Sousa, C., Pereira, M., \& Pereira, M. G. (2019). Quality of life in patients with multiple sclerosis: A study with patients and caregivers. Disability and Health Journal, 12, 628-634.

Shaharir, S., \& Gordon, C. (2016). Constitutional symptoms and fatigue in systemic lupus erythematosus. In G. C. Tsokos (Ed.), Systemic lupus erythematosus: Basic, applied and clinical aspects (pp. 317-324). Academic Press. doi:10.1016/B978-0-12-801917-7.00037-1

Skevington, S., Lotfy, M., \& O'Connell, K. (2004). The World Health Organization's WHOQOLBREF quality of life assessment: Psychometric properties and results of the international field 
trial. A report from the WHOQOL Group. Quality of Life Research : an International Journal of Quality of Life Aspects of Treatment, Care and Rehabilitation, 13(2), 299-310.

Tench, C., Bentley, D., Vleck, V., McCurdie, I., White, P., \& D’Cruz, D. (2002). Aerobic fitness, fatigue, and physical disability in systemic lupus erythematosus. The Journal of Rheumatology, 29(3), 474-481.

Tench, C., McCurdie, I., White, P., \& D’Cruz, D. (2000). The prevalence and associations of fatigue in systemic lupus erythematosus. Rheumatology, 39(11), 1249-1254.

Vaz-Serra, A., Canavarro, M., Simões, M., Pereira, M., Gameiro, S., Quartilho, M., ... Paredes, T. (2006). Estudo psicométricos do instrumento de avaliação da qualidade de vida da Organização Mundial de Saúde (WHOQOL-100) para português de Portugal. Psiquiatria Clínica, 27(2), 31-40.

Weinberg, S. L., Gandhi, N., Arora, S., Sequeira, W., Sengupta, M., Block, J. A., \& Jolly, M. (2018). Body image in lupus: Is it disease activity, physical function, depression, pain, fatigue, sleep, fibromyalgia or stress? International Journal of Clinical Rheumatology, 13(4), 250-257.

Zhang, L., Fu, T., Yin, R., Zhang, Q., \& Shen, B. (2017). Prevalence of depression and anxiety in systemic lupus erythematosus: A systematic review and meta-analysis. BMC Psychiatry, 17(1), 70 .

Zigmond, A., \& Snaith, R. (1983). The hospital anxiety and depression scale. Acta Psychiatrica Scandinavica, 67(6), 361-370.

Zonana-Nacach, A., Roseman, J., McGwin, G., Friedman, A., Baethge, B., \& Reveille, J. (2000). Systemic lupus erythematosus in three ethnic groups. VI: Factors associated with fatigue within 5 years of criteria diagnosis. Lupus, 9(2), 101-109. 